\title{
Novel Mycoplasma Agalactiae with new P30 Protein Pattern by Major Change in 17 Amino Acids
}

\author{
M. Babazadeh ${ }^{1}$, S. A. Pourbakhsh ${ }^{2}$, Z. Noormohammadi ${ }^{1}$, M. Esmaelizad ${ }^{3}$ \& H. Goudarzi ${ }^{2}$ \\ ${ }^{1}$ Department of Biology, Science and Research Branch, Islamic Azad University, Tehran, Iran \\ ${ }^{2}$ Mycoplasma Reference Laboratory, Razi Vaccine and Serum Research Institute, Agricultural Research, \\ Education and Extension Organization (AREEO), Karaj, Iran \\ ${ }^{3}$ Central Laboratory Department, Razi Vaccine and Serum Research Institute, Agricultural Research, Education \\ and Extension Organization (AREEO), Karaj, Iran
}

Correspondence: Pourbakhsh S. A.,Mycoplasma Reference Laboratory, Razi Vaccine and Serum Research Institute, Agricultural Research, Education and Extension Organization (AREEO), Karaj, Iran. E-mail: poursaba@chmail.ir

Received: November 16, 2017

Accepted: December 14, 2017

OnlinePublished: January 1, 2018

doi: $10.5539 /$ jmbr.v8n1p8

URL: https://doi.org/10.5539/jmbr.v8n1p8

\begin{abstract}
M. agalactiae (Mycoplasma agalactiae) is the main agent of CA (contagious agalactia) that is primarily disease of dairy sheep and goats. In Iran, a three-valent Agalactia inactivated vaccine were prepared based on three M. agalactiae isolated from milk secretion of sheep and goat of Taleghan, Shiraz and Lorestan and preventive policies against CA disease founded in Razi Institute since 1966. The P30 is a specific and stable lipoprotein of M. agalactiae. In this study, complete coding sequence of P30 gene of three Iranian vaccine strains and ten recently field isolates were analyzed in nucleotide and protein levels by bioinformatics tools. Interestingly, results observed a novel protein pattern $\mathrm{K}_{106}$ VLKTKEIRLSQERKLS $_{122}$ in P30 protein of vaccine strains compared to field isolates and the other available sequences in GenBank. Our findings demonstrated different B and T cell epitope patterns in Iranian vaccine strains. We suggested that the major change in P30 protein pattern may be occurred due to mutation during adaptation process in PPLO (Pleuropneumonia-Like Organisms) broth media.
\end{abstract}

Keywords: Mycoplasma agalactiae, Contagiousagalactia, P30, Vaccine, Sheep and goat

\section{Introduction}

Contagious agalactia (CA) is primarily a disease of dairy sheep and goats characterized by mastitis, arthritis and keratoconjunctivitis (Amores et al., 2010, Nicolas et al., 2008, Stear, 2005). This syndrome is produced by Mycoplasma agalactiaeand causes the reduction and the suppression of milk production and death in many young animals (Katarína et al., 2009, Madanat et al., 2001, Tola et al., 1997).

CA is found across several countries, including mainly North America, western Asia, North Africa, Europe and is endemic in most Mediterranean countries (Zendulkova et al., 2007, Bergonier et al., 1997).

Borry and Entessar (1963) reported the presence of Agalactia disease in small ruminant for the first time in Iran and also Sotoodehnia and Aarabi (1986) identified CA as cause of economic losses in most part of Iran.

Phase variation of surface lipoproteins is a common mechanism in mycoplasma species and is probably a major adaptive strategy for these minimal pathogens (Nouvel et al., 2010). Ability of mycoplasma to evade the immune response of the hosts, leading to facilitate chronic infection (Browning et al., 2011). Most importantly, prevention and eradication of CA can be obtained through better diagnostic tests and through a more efficient vaccine (Greco et al., 2002).

Nowadays, attention has been paid to the interaction betweenlipoproteins and pathogenicity of M. agalactiae videlicet the lipoproteins appear to play a prominent role in adherence, in enzymatic interactions, in transport of nutrients and finally in facilitate chronic infection with both inducing the hostimmune response and evasion of thisresponse (Browning et al., 2011, Bergonier et al., 1996).

Zavagli (1951) had succeeded to prepared Formalin-inactivated Agalactia vaccine in Italy. Effective Agalactia vaccines were prepared using washed cultures inactivated with phenol-saponin by Tola et al. (1999). Greco et al. 
(2002), indicated a good efficacy of the vaccine which inactivated by oil-emulsion in eliciting protection against M. agalactiae infection.In Iran, three-valent Agalactia vaccine which inactivated with saponin were prepared based on threeM. agalactiae isolated from milk secretion of sheep and goats of different geographic areas in Razi Institute since 1971 (Naseri Radet al., 2007).

With due attention to production of Agalactia vaccine against CA in Iran since 46 years ago and with the aim to raise of efficiency of current vaccine, it seems necessary to evaluated specific and stable lipoproteins of M. agalactiae.

The P30 gene is a stable, specific andstrongly immunogenic antigen for M. agalactiae as the immune response against P30 is strong and persistent. Immunoblot analysis using the monospecific polyclonalanti-P30-His serum indicated that P30 is specific to this pathogen means presence this gene in all M. agalactiae strainstested and absence in the other mycoplasma species (Fleury et al., 2001).

It is important to understand the properties of protein sequences that are important for antigenicity and to identify peptide epitopes whose utilization result in the development and optimization of vaccines (Fleri et al., 2017, Jones et al., 2014, Schlehuber et al., 2011, Leroux-Roels., 2010).

In this study the P30 gene of three M. agalactiae vaccine strains of Razi Vaccine and Serum Research Institute were analyzed and compared to new field isolated from different provinces of Iran and all other sequences available in GenBank.

\section{Materials and Methods}

\subsection{Sampling and Culture Methods}

In this study, three vaccine strains of M. agalactiae were taken from Department of Aerobic Bacterial Vaccine Production Laboratory of Razi Institute and cultured with ten new field isolates which were isolated from different provinces of Iran (Table 1). Samples were collected from eye and milk secretion of sheep and goat herds with clinical signs of infection of mycoplasma, transported in transport medium and transmitted on ice to the mycoplasma Reference Laboratory of Razi Institute, Karaj, Iran. The specimens were diluted and filtered into the fresh Pleuropneumonia-Like Organisms (PPLO) broth media and then inoculated on to PPLO agar medium (BBL, Becton Dickinson and company, Cockeyville, Sparks, MD). Inoculated agar and broth were incubated at $37^{\circ} \mathrm{C}$ in $5 \% \mathrm{Co} 2$ and $98 \%$ humid atmosphere. The broths were observed daily for signs of growth and the plates were considered for the typical appearance of mycoplasma colonies. M. agalactiae reference strain (NCTC 10123) and uncultured PPLO broth have used as a positive and negative controls respectively.

Table 1. M. agalactiae samples which were used in this study

\begin{tabular}{lllllll}
\hline \multirow{2}{*}{ Grouping } & Iranian samples ID & Isolation area & $\begin{array}{l}\text { GenBank } \\
\text { accession numbers }\end{array}$ & Year of isolation & Host & Source \\
\hline Group No. I & IR(1) Vaccine & Taleghan & MF380352 & 1966 & Goat & Milk \\
& IR(2) Vaccine & Shiraz & MF380353 & 1966 & Sheep & Milk \\
& IR(3) Vaccine & Lorestan & MF380354 & 1966 & Sheep & Milk \\
Group No. II & IR(4)9025 & Kurdistan & MF380360 & 2011 & Sheep & Milk \\
& IR(5)9078 & Kurdistan & MF380361 & 2011 & Goat & Milk \\
& IR(6)9079 & Kurdistan & MF380362 & 2011 & Goat & Milk \\
& $\operatorname{IR}(7) 9004$ & Kurdistan & MF380363 & 2011 & Sheep & Milk \\
& $\operatorname{IR}(8) 4003$ & Khoozestan & MF380364 & 2010 & Sheep & Eye \\
& $\operatorname{IR}(9) 6115$ & Golestan & MF380356 & 2012 & Goat & Eye \\
& $\operatorname{IR}(10) 6126$ & Golestan & MF380357 & 2012 & Goat & Milk \\
& $\operatorname{IR}(11) 6130$ & Golestan & MF380358 & 2012 & Goat & Milk \\
& $\operatorname{IR}(12) 10090$ & Eilam & MF380359 & 2011 & Sheep & Milk \\
& $\operatorname{IR}(13) 2264$ & Kerman & MF380355 & 2012 & Goat & Milk \\
\hline
\end{tabular}

\subsection{DNA Extraction and PCR Amplification}

DNA was extracted from samples using phenol-chlorform method developed by Tola et al. (1997).

Identification of genus and species of isolates were performed with published primers set based on 16SrRNA and P80 lipoprotein genes (van Kuppeveld et al., 1992; Tola et al., 1997) respectively according to protocol described by Tola et al. (1996). 
Two primers P30F: 5'-GCA GTT TTA AAT AAC ACA GG-3' and P30R: 5' AAA TCT TGC GCG CAG CAA GA-3' were designed in ORF region of $\mathrm{P} 30$ gene by Oligo 5.0 software. P30 coding sequence was amplified by polymerase chain reaction: The PCR mix for amplification of P30 gene was performed in a total volume of $50 \mu 1$, containing: $5 \mu 1$ of 10 X PCR buffer (CinnaGen, Iran), $2 \mathrm{mM} \mathrm{MgCl} 2,1 \mu \mathrm{dNTP} \operatorname{mix}(10 \mathrm{mM}), 1 \mu \mathrm{l}$ of each primer $(10 \mathrm{pM}), 0.2 \mu \mathrm{lof}$ Taq DNA polymerase (CinnaGen, Iran), and $100 \mathrm{ng}$ of extracted genomic DNA as the template.

The thermal program was conducted in a Gradient Mastercycler (Eppendorf, Germany) as follows: 3 min at $95^{\circ} \mathrm{C}$, followed by 38 cycles of $1 \mathrm{~min}$ at $93^{\circ} \mathrm{C}, 30 \mathrm{~s}$ at $54^{\circ} \mathrm{C}$ and $40 \mathrm{~s}$ at $72^{\circ} \mathrm{C}$, with a final extension cycle of $5 \mathrm{~min}$ at $72^{\circ} \mathrm{C}$. The PCR bands were visualized by UV transilluminator after electrophoresis $(1 \%$ agarose gel in $1 \times$ Tris-acetic acid-EDTA (TAE) buffer) and ethidium bromide staining.

\subsection{Sequencing and Phylogenetic Analysis}

Complete coding sequences of P30 gene of thirteen Iranian M. agalactiae isolates were sequenced in both directions by Sanger method (Macrogen Company). Nucleotide and protein sequences of P30 were compared and percentage of divergence was calculated by MegAlign software.

\subsection{Epitopes Prediction}

$\mathrm{B}$ and T-cells epitopes were predicted in P30 protein by online IEDB (Immune Epitope Database and Analysis Resource) software with consensus method and consider cutoff $\leq 1 \%$ for all lengths of $\mathrm{H}-2-\mathrm{Kd}, \mathrm{H}-2-\mathrm{Dd}, \mathrm{H}-2-\mathrm{Ld}$ alleles of MHC- Iand $\leq 8.6$ for all lengths of H2-IAd, H2-IEd alleles of MHC-II in mouse. http://www.iedb.org/

\subsection{Database Submission}

P30 sequences of three vaccine strains and ten field isolates of Iranian M. agalactiae were submitted to the GenBank databases under accession numbers MF380352 to MF380364 which were released to the public database on Jan 1, 2018. https://www.ncbi.nlm.nih.gov/WebSub/?tool=genbank

\section{Results}

\subsection{Culture and PCR}

Ten field isolates of M. agalactiae which were isolated from 5 provinces of Iran and also three vaccine strains were proved by culture and PCR methods. The results of culture proved the presence of mycoplasma in all the samples that weregrown in PPLO broth media and also observation colonies on PPLO agar media. Genus and species were detected by observation of PCR amplicons with $163 \mathrm{bp}$ and $375 \mathrm{bp}$ length respectively with published primers set were used for the specific detection of M.agalactiae and we success to detected this pathogen with both methods. The complete coding sequence of P30 gene with $800 \mathrm{bp}$ length was amplified in all field isolates andthree Iranian vaccine strains of $M$. agalactiaesuccessfully. Briefly, in all studied field isolates and vaccine strains, the DNA fragment of Mycoplasma genus with approximately $163 \mathrm{bp}$ of 16SrRNA and the M. agalactiae species in $375 \mathrm{bp}$ and 800 bp of P80 and P30 lipoprotein genes were amplified respectively by Polymerase Chain Reaction (Figure 1).

A

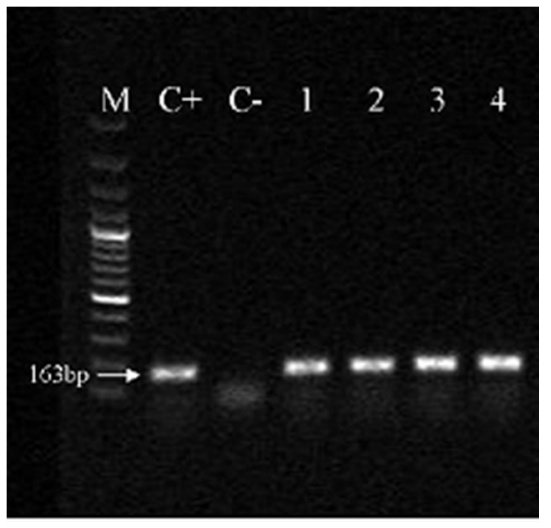

B

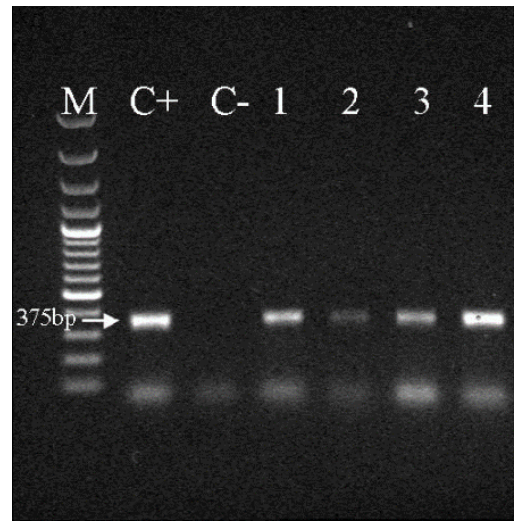

C

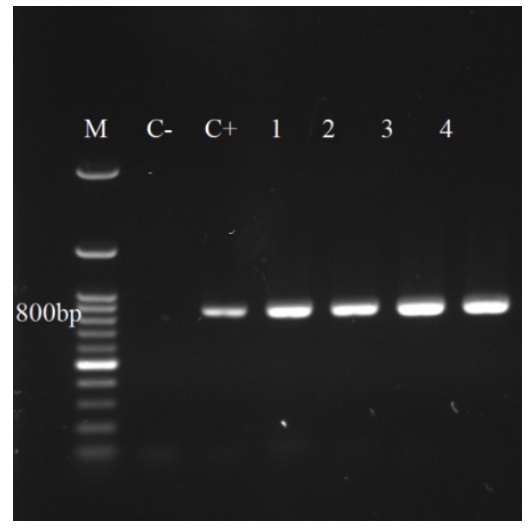

Figure 1. A: Mycoplasma genus PCR, B: Mycoplasma agalactiaePCR, C: P30-PCR

PCR electrophoresis analysis in \%1 gel agarose. M: Marker (100bp DNA ladder). $C+$ : Positive control (reference strain (NCTC 10123)), C-: Negative control (uncultured PPLO broth) and Lane 1 to 4 are the Mycoplasma isolates in this study 


\subsection{Nucleotide Sequence Analysis of Complete Coding Sequence of P30 Gene}

P30 nucleotide sequences were analyzed by MegAlignsoftwares. The results identified two major groups with more than 11 percent divergence. Group No.I include three vaccine strains which were isolated from Shiraz, Taleghan and Lorestan in 1966 and group No.II include other ten field isolates from five different provinces of Iran from 2010-2012. It is clearly in phylogenetic tree, three vaccine strains made a unique distinct group with 11 percent divergence (Figure 2). Comparison study between two groups revealed insertion sequences $\left(\mathrm{G}_{349}, \mathrm{~A}_{350}\right.$ and $\mathrm{T}_{402}$ )in the position 349-402 of nucleotide alignment that causes two frame shifts in nucleotide sequence of P30 gene (Figure 3).

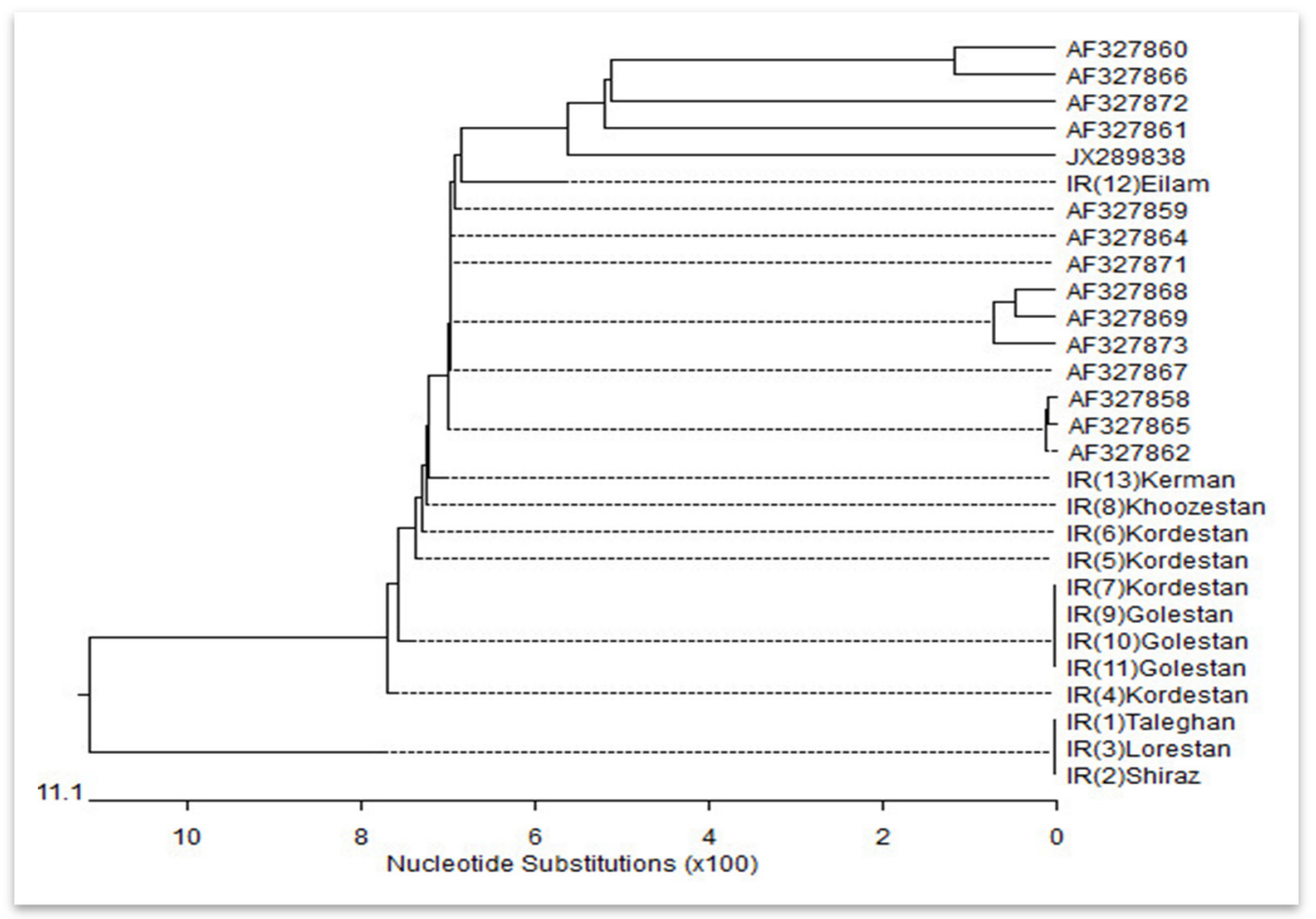

Figure 2. Phylogenetic tree with Neighbor joining clustering method, IR(1-3) are vaccine strains of Iran, IR(4-13) are field isolates of Iran and the other samples are submitted in the GenBank

\begin{tabular}{|l||}
\hline Q Consensus \\
28 Sequences \\
\hline IR (1) Taleghan \\
IR (2) shiraz \\
IR (3) lorestan \\
IR (4) Kordestan \\
IR (5) Kordestan \\
IR (6) Kordestan \\
IR (7) Kordestan \\
IR (8) Khoozestan \\
IR (9) Golestan \\
IR (10) Golestan \\
IR (11) Golestan \\
IR (12) Elam \\
IR (13) Kerman \\
AF327858 \\
AF327859 \\
AF327860 \\
AF327861 \\
AF327862 \\
AF327864 \\
AF327865 \\
AF327866 \\
AF327867 \\
AF327868 \\
AF327869 \\
AF327870 \\
AF327871 \\
AF327872 \\
Af327873 \\
\hline
\end{tabular}

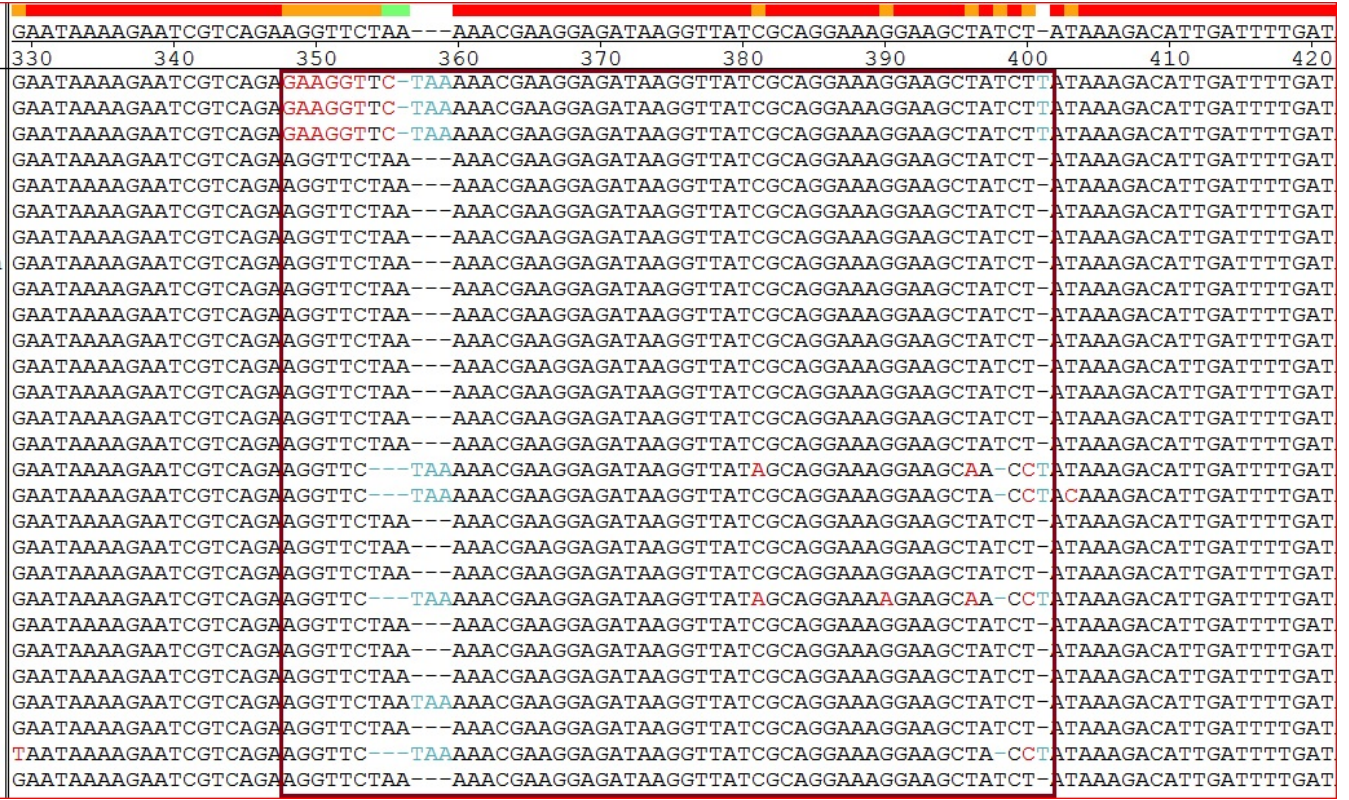

Figure 3. Nucleotide alignment, IR(1-3) are vaccine strains of Iran, IR(4-13) are field isolates of Iran and the other samples are submitted in the GenBank 
Multiple alignment showed $(4.7 \leq \mathrm{D} \leq 8.6)$ percent divergence between P30 nucleotide sequences and P30 pseudogenes. Divergency within P30 genes was $(\mathrm{D} \leq 1.4) \%$ and $(\mathrm{D} \leq 2.3) \%$ in nucleotide and protein levels respectively (D: Diversity).

\subsection{InsilicoAnalysis of P30 Protein Pattern in Vaccine and Field Isolates}

Alignment of P30 protein sequences by MegAlign software showed some important differences between vaccine strains and all field isolates. The most importance differences caused by the variation happened in the position 348-401 of nucleotide alignment in three vaccine strains of group No.I that caused two frame shifts in nucleotide sequence of $\mathrm{P} 30$ gene which were substitute17 amino acids in residues 106-122 (Figure 4).Two different patterns including $\mathrm{K}_{106}$ VLKTKEIRLSQERKLS $_{122}$ (Pattern A, belong to group No.I) and $\mathrm{G}_{106} \mathrm{~S}-\mathrm{KNEGDKVIAGKEAI}_{121}$ (Pattern B, belong to group No.II) was detected between two P30 groups(Figure 4). Furthermore a unique amino acid insertion (Lysine108) was observed in group No.I and also for the first time a unique amino acid substitute $\left(\mathrm{S}_{63} \rightarrow \mathrm{Y}_{63}\right)$ in more than $92 \%$ of Iranian M. agalactia isolates was detected.Considerable, that all of the Iranian mycoplasma isolates in group No.II showed similar pattern with available sequences in GenBank based on P30 gene. But P30 protein pattern of vaccine strains in group No.I was unique among available data in DATA bases (2017 May 21).

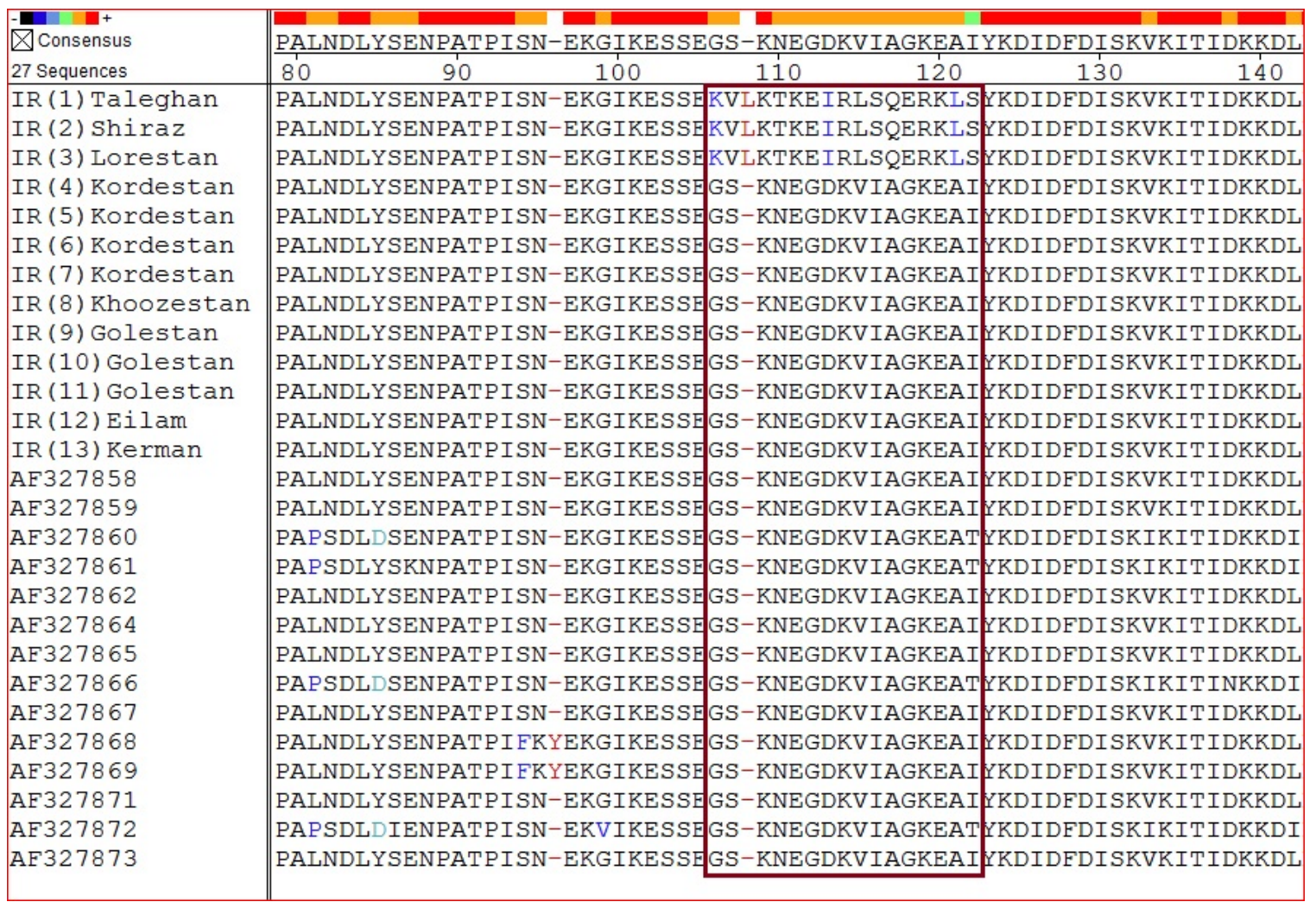

Figure 4. Amino acid alignment, IR(1-3) are vaccine strains of Iran, IR(4-13) are field isolates of Iran and the other samples are submitted in the GenBank

\subsection{Comparing B and T Cells Epitope Patterns}

Different $B$ and $T$ cells epitope patterns were identified in polymorphic region (106 to 122) of P30 protein among two distinct groups of Iranian M. agalactiae based on IEDB analysis resource. In polymorphic region of P30 protein, two (114-RLS-116 and 120-KLSY-123) and one (125-AIY-127) specific B cell epitopes in group No.I and II were identified respectively. The results of MHC class II binding prediction showed four epitopes in pattern A of H2-IAd allele but havent any epitopes in pattern B. In other hand for H2-IEd allele of MHC- II none epitopes were detected in two different $\mathrm{P} 30$ patterns. MHC class I binding prediction demonstrated different results for each three alleles available in mouse. In the H-2-Kd allele, we recognized two and one epitopes for pattern A and B respectively. H-2-Dd allele showed any epitopes for two studied polymorphic patterns and for H-2-Ld allele, an epitope was identified for pattern A and none in pattern B (Table 2). 
Table 2. B \& T Cells Epitopes Prediction in polymorphic region of P30 protein of M. agalactiae

\begin{tabular}{|c|c|c|c|c|c|c|}
\hline & Allele & Pattern & start & end & peptide & length \\
\hline \multirow{3}{*}{ B cell } & \multirow{3}{*}{-} & \multirow{2}{*}{ A } & 114 & 116 & RLS & 3 \\
\hline & & & 120 & 123 & KLSY & 4 \\
\hline & & $\mathrm{B}$ & 125 & 127 & AIY & 3 \\
\hline \multirow{7}{*}{ MHC class II binding } & \multirow{5}{*}{ H2-IAd } & \multirow{5}{*}{ A } & 106 & 120 & ESSEKVLKTKEIRLS & 15 \\
\hline & & & 107 & 121 & SSEKVLKTKEIRLSQ & 15 \\
\hline & & & 108 & 122 & SEKVLKTKEIRLSQE & 15 \\
\hline & & & 109 & 123 & EKVLKTKEIRLSQER & 15 \\
\hline & & & None & & & \\
\hline & \multirow{2}{*}{ H2-IEd } & A & None & & & \\
\hline & & B & None & & & \\
\hline \multirow{7}{*}{ MHC class I binding } & \multirow{3}{*}{$\mathrm{H}-2-\mathrm{Kd}$} & \multirow{2}{*}{ A } & 126 & 134 & SYKDIDFDI & 9 \\
\hline & & & 126 & 139 & SYKDIDFDISKVKI & 14 \\
\hline & & B & 118 & 126 & KVIAGKEAI & 9 \\
\hline & \multirow{2}{*}{ H-2-Dd } & A & None & & & \\
\hline & & B & None & & & \\
\hline & \multirow{2}{*}{ H-2-Ld } & A & 125 & 132 & LSYKDIDF & 8 \\
\hline & & $\mathrm{B}$ & None & & & \\
\hline
\end{tabular}

MHC class II binding Epitopes Prediction in polymorphic region of P30 protein of M. agalactiae

-For MHC class II epitope predictions, selection of predicted binders can be done based on the percentile rank or MHC binding affinity.The IEDB currently recommends making selections based on a consensus percentile rank of the top $10 \%$.Alternatively, selecting peptides predicted to bind at $1,000 \mathrm{nM}$ is also supported by experimental data (Southwoodet al., 1998).

MHC class I binding Epitopes Prediction in polymorphic region of $\mathrm{P} 30$ protein of M. agalactiae

For MHC class I epitope predictions, selection of predicted binders can be done based on the percentile rank or MHC binding affinity. The IEDB currently recommends making selections based on a percentile rank of $<=1 \%$ for each (MHC allele, length) combination to cover most of the immune responses.

\section{Discussion}

Protein pattern of an immunodominant antigen, P30, was evaluated from three vaccine strains and compared belong to Iranianrecentlyfield isolates of M. agalactiae.

The three vaccine strains of Razi vaccine and Serum Research Institute which were used in three-valent Agalactia inactivated vaccine production were introduced as a new strain with novel P30 protein pattern.

Three effective monovalent Agalactia vaccines which inactivated with formalin, phenol-saponin and oil-emulsion were prepared by Zavagli et al. (1951), Tola et al. (1999) and Greco et al. (2002) respectively. Vaccines which inactivated with formalin, heat or sodium hypochlorite and then adjuvanted with aluminum hydroxide did not provided significant protection (Tola et al., 1999). The mineral-oil, phenol or saponin-inactivated vaccine were highly immunogenic which produced a progressive increase in antibody production and enable to induced a fully protective preventing not only the clinical signs of CA but also the infection by M. agalactiae even at 8 months post-vaccination (Tola et al., 1999, De la Fe et al., 2007, Buonavoglia et al., 2007).

In Iran, an inactivated and saponinized vaccine has been prepared with different $M$. agalactiae isolates against CA in 1971 (Naseri Rad et al., 2007). Baharsefat et al. (1971) announced the three-valent saponinized vaccine with good protectivity remain immune for 6 - 9 months post-vaccination.

Prevalence evaluated of CA syndrome in sheep and goat herds of Iran based on previous studies between years 1986-2011 showed approximately 20\% outbreak from 1986 to 2007 but a high Ascending Course was occurred and rate of disease had significant increased until 33.3\% in 2011(Kheirkhah et al., 2011, PiraliKheirabadi \& Ebrahimi., 2007, Sotoodehnia \& Aarabi., 1986). 
Evidence related to an increase in prevalence has led to the conclusion that development of effective Agalactia vaccines through knowledge of the stable, specific and main immunogenic antigens of $M$. agalactiae is the most promising approach to control $M$. agalactiae infections in small ruminant.

Previous studied showed that $\mathrm{P} 30$ is a stable, specific and strongly immunodominant protein of M. agalactiae thus this gene presented as a suitable candidate for determined ELISA (Enzyme-Linked ImmunoSorbent Assay) kit manufactured and recombinant vaccine against CA (Fleury et al., 2001, Fleury et al., 2002).

The results of this study were in agreement of Fleury et al (2001) report that P30 is specific gene and detected in all of $M$. agalactiae which were isolated from Iran. Nucleotide sequences of P30 gene proved conservative of this gene (98\% to $100 \%$ identity) among available sequences in GenBank and $77 \%$ of Iranian samples (Table 1).

Comprehensive bioinformatics analysis of $\mathrm{P} 30$ gene of $M$. agalactiae showed some importance differences in the ORF region that caused a considerable variation among two groups of Iranian isolates.

For the first time, unlike to previous studies, in three Iranian vaccine strains a new P30 protein pattern was identified. These novel M. agalactiae was located in new distinct group namely group No.I with 6-9\% divergency in nucleotide sequences and 6-11\% in amino acid levels respectively (Table 1).

Bergonier et al. (1996) studied 245 field isolates originating from ten different countries to find an antigenic variability of $M$. agalactiae with species-specific monoclonal antibodies (MAbs) were developed against M. agalactiae reference strain PG2. Their results indicated that the antigenic variability of M. agalactiae partially related to the geographic origin of the isolates (Bergonier et al., 1997, Bergonier et al., 1996). This study was agree with them to indicated antigenic variability in isolates which were isolated from different region of Iran based on P30 protein.

Many of the researchers studied on various gene of M.agalactiae to detected genetic diversity and variations but concentration on the P30 gene close to the Fleury et al (2001) that they studied on the P30 gene of 15 samples of M.agalactiae. They detected a similar pattern in ORF region of P30 gene while, in the present study 13 samples which were isolated from 8 provinces of Iran were considered and some importance differences were detected in the P30 ORF region of M.agalactiae(Table 1).

The most importance differences were the variation happened in the position 348-401 and insertion sequences $\left(\mathrm{G}_{349}, \mathrm{~A}_{350}\right.$ and $\left.\mathrm{T}_{402}\right)$ of nucleotide alignment in three vaccine strains of group No.I that caused two frame shifts in nucleotide sequence of P30 gene which were substitute17 amino acids in residues 106-122 (Figure 2, Figure 3 ,Figure 4). Further analysis of amino acid alignment, indicated a Lysine $\left(\mathrm{L}_{108}\right)$ insertion in the Iranian isolates of group No.I (Taleghan, Shiraz and Lorestan). This pattern only showed in three Iranian vaccine strains and no detected in the other sequences of Iran and available in Database.

Strategy of mycoplasmas for avoiding genome erosion is Sharing genetic resources via horizontal gene transfer that may provide this pathogen for adapting to new niche or host (Sirand-Pugnet et al., 2007). Adaptation of $M$. agalactiae isolates to new environment needed the time and when adapted to laboratory conditions, these grow easily in commonly used media for mycoplasma growth freshly (Srivastava., 1982, Kumar et al., 2014).

Date of sample collection of these three old isolates back to 1966 whereas the other recently samples were collected from 2010 to 2012. Old isolates are routinely used as a master seed for production of contagious agalactia vaccine since 1966 in Razi Vaccine and Serum Research Institute of Iran. Based on scientifically evidence this genetic diversity occurred in vaccine isolates, maybe due to mutation during adaptation process and highly serial passages in PPLO broth media.

Furthermore, evaluation of P30 gene showed several differences between the active geneand submmited sequences of pseudogene in the GenBank. For example there was a cytosine (CCA) in residue 275 of nucleotide sequences of pseudo genes (AF327860- AF327861- AF327866- AF327872) while in the same position of all the genes was thymine (CTA) that caused to convert genetic code of proline to leucine. Also, in the nucleotide sequences of pseudogene some other mutations were detected: $\mathrm{C}_{382} \rightarrow \mathrm{A}, \mathrm{T}_{397} \rightarrow \mathrm{A}$, deletion of $\mathrm{T}_{399}, \mathrm{~T}_{401} \rightarrow \mathrm{C}$, insertion of $\mathrm{T}_{402}, \mathrm{~A}_{428} \rightarrow \mathrm{T}, \mathrm{G}_{432} \rightarrow \mathrm{A}$. Besides, stop codon (TGA) in the position 562 situated in nucleotide sequences of pseudogenes while Tryptophan codon (TGG) in the same positions has been observed in the genes.

Clinical and basic biomedical researchers are interested to epitopes investigation for vaccine design, disease prevention, diagnosis, and treatment (Ruthet al., 2015, Wang et al., 2008). Recombinant DNA can be a proper alternative way against whole pathogen-formulations in vaccination, capable of stimulating a specific immune response (Soria-Guerra et al., 2015). In the present study, epitopes prediction were done for variable area of P30 lipoprotein (position 106-122 of amino acid alignment) of M. agalactiae in two groups of Iranian isolates with the aim ofrecombinant vaccine design or specific antibodies to Differential Diagnosis of field isolates and vaccine 
strains. All the mouse alleles of B and T cells were analyzed in IEDB analysis resource and determined differential epitope patterns in this region.

Increased prevalence of CA syndrome up to $13 \%$ in recent years in Iran, might be occurred due to major change in antigenic region of immunodominant antigens of M.agalactiae likeness P30 protein that caused the possible reduction of protectivity of three-valent vaccine which made 46 years ago.

It seams that the polyvalentrecombinantvaccinecontaining two patterns of specific and immunodominant $\mathrm{P} 30$ gene can be better protects against several strains of M.agalactiae in Iran.

\section{Conclusion}

In this study, three novel M. agalactiae was identified based on P30 protein pattern. These three vaccinal strains showed new pattern and different B and T-cells epitopes in P30 protein compare to field isolates and the other available sequences in NCBI DATA bases. Additional studies are needed for better understanding about P30 protein structure of $M$. agalactiae and also immune study is required to promote the effectiveness of current CA vaccine for preventing infections.

\section{Funding}

This study was supported by a project with the grant No.2-18-18-94133of Razi Vaccine and Serum Research Institute, Agricultural Research, Education and Extension Organization (AREEO), Karaj, Iran.

\section{Conflicts of interest}

The authors have no financial conflicts of interest to disclose.

\section{Acknowledgements}

We thank all the staff of Mycoplasma Reference Laboratory and Central Laboratory, Razi Vaccine and Serum Research Institute, Karaj, Iran.

\section{References}

Amores J, Corrales J. C, Martin A. G, Sanchez, A., \& Conteras, A. (2010). Comparison of culuture and PCR to detect Mycoplasma agalactiae and Mycoplasma mycoides subsp. Capri in ear swabs taken from goats. Veterinary Microbiology, 140, 105-108. https://doi.org/10.1016/j.vetmic.2009.06.036

Baharsef, at M., Yamini, B., \& Ahourai, P. (1971). Mycoplasma Agalactiae V -Comparison of three different contagions agalactia vaccine. Arch.Razi, 23, 113-118.

Baharsefat, M., \& Yamini, B. (1971) Mycoplasma agalactiae IV -Immunisation contre l'agalactiae contagieuse des ovins et des caprins. Arch Razi, 23, 107-111.

Bergonier, D., Berthelot, X., \& Pourmarat, F. (1997). Contagious agalactiae of small ruminants current of knowledge concerning epidemiology diagnosis and control. Review Science Techenology, 16(3), 848-873. https://doi.org/10.20506/rst.16.3.1062

Bergonier, D., Simone, F., Russo, P., Solsona, M., Lambert, M., \& Poumarat, F. (1996) Variable expression and geographic distribution of Mycoplasma agalactiae surface epitopes demonstrated with monoclonal antibodies. FEMS Microbiollogy Letters, 143, 159-165. https://doi.org/10.1111/j.1574-6968.1996.tb08475.x

Borry, G., \& Entessar, F. (1963) Etude sur l"agalaxie des chevres et des moutons en Iran. Arch. Razi, 15, 45-61.

Browning, G. F., Marenda, M. S., Noormohammadi, A. H., \& Markham, P. F. (2011) The central role of lipoproteins in the pathogenesis of mycoplasmoses. Vet. Microbiol, 153, 44-50. https://doi.org/10.1016/ j.vetmic.2011.05.031

Buonavoglia, D., Greco, G., Corrente, M., Greco, M. F., Abramo, M. D., Latronico, F., ... Decaro, N. (2010). Long-term immunogenicity and protection against Mycoplasma agalactiae induced by an oil adjuvant vaccine in sheep. Research in veterinary science, $88,16-19$. https://doi.org/10.1016/j.rvsc.2009.07.006

De la Fe, C., Assuncao, P., Saavedra, P., Tola, S., Poveda, C., \& Poveda, J. (2007) Field trial of two dual vaccines against Mycoplasma agalactiae and Mycoplasma mycoides subsp. mycoides (large colony type) in goats. Vaccine, 25, 2340-2345. https://doi.org/10.1016/j.vaccine.2006.11.050

Fleri, W., Paul, S., Kumar Dhanda, S., Mahajan, S., Xu, X., Peters, B., \& Sette, A. (2017) The Immune Epitope Database and Analysis Resource in Epitope Discovery and Synthetic Vaccine Design. Front Immunol, 8, 27. https://doi.org/10.3389/fimmu.2017.00278 
Fleury, B., Bergonier, D., Berthelot, X., Peterhans, E., Frey, J., \& Vilei, E. M. (2002) characterization of P40, a cytoadhesin of Mycoplasma agalactiae. Infectection Immunology, 70, 5612-5621. https://doi.org/10.1128/ IAI.70.10.5612-5621.2002

Fleury, B., Bergonier, D., Berthelot, X., Schlatter, Y., Frey, J., \& Vilei, E. M. (2001) Characterization and Analysis of a Stable Serotype-Associated Membrane Protein (P30) of Mycoplasma agalactia. J Clin Microbiol, 39, 2814-2822. https://doi.org/10.1128/JCM.39.8.2814-2822.2001

Greco, G., Corrente, M., Buonavoglia, D., Aliberti, A., \& Fasanella, A. (2002) Inactivated vaccine induces protection against Mycoplasma agalactiae infection in sheep. New Microbiol, 25, 17-20.

Jones, S., Asokanathan, C., Kmiec, D., Irvine, J., Fleck, R., Xing, D., ... Coote, J. (2014) Protein coated microcrystals formulated with model antigens and modified with calcium phosphate exhibit enhanced phagocytosis and immunogenicity. Vaccine., 32, 4234-4242. https://doi.org/10.1016/j.vaccine.2013.09.061

Katarína, O., Lorena, L. E., David, R. L., \& Marta, H. (2009) Mycoplasma agalactiae p40 Gene, a Novel Marker for Diagnosis of Contagious Agalactia in Sheep by Real-Time PCR: Assessment of Analytical Performance and In-House Validation Using Naturally Contaminated Milk Samples. J Clin Microbiol., 47, 445-450. https://doi.org/10.1128/JCM.01442-08

Kheirkhah, B., Pourbakhsh, S. A., Nadalian, M. G., Banani, M., \& Ashtari, A. (2011) Detection of Mycoplasma agalactiae by culture and polymerase chain reaction (PCR) methods from Iranian goats. Afr Microbiol Res, 5 , 1668-1672. https://doi.org/10.5897/AJMR11.359

Kumar, A., Rahal, A., Chakraborty, S., Kumar Verma, A., \& Dhama, K. (2014) Mycoplasma agalactiae, an Etiological Agent of Contagious Agalactia in Small Ruminants. Hindawi Publishing Corporation Veterinary Medicine International. $\mathrm{http}: / / \mathrm{dx}$. doi.org/10.1155/2014/286752

Leroux-Roels, G. (2010) Unmet needs in modern vaccinology: adjuvants to improve the immune response. Vaccine, 28, 25-36. https://doi.org/10.1016/j.vaccine.2010.07.021

Madanat, D., Zendulková, Z., \& Pospí, I. L. (2001) Contagious agalactia of sheep and goats: a review. Acta Vet. Brno, 70, 403-412. https://doi.org/10.2754/avb200170040403

Naseri Rad, A., Moazenijula, A., Sotoodehnia, A., \& Jabbari, A. (2007) Preparation of agalactia vaccine in fermentor .Arch Razi, 62, 45-48

Nicolas, R., Ayling, R., \& McAuliffe, L. (2008) Mycoplasma diseases of ruminants. Small Ruminant Research. OIE. (2008). Contagious Agalactiae: 98-114. https://doi.org/10.1079/9780851990125.0000

Nouvelk L. X., Sirand-Pugnet, P., Marenda, M. S., Sagné, E., Barbe, V., Mangenot, S., .. Citti, C. (2010) Comparative genomic and proteomic analyses of two Mycoplasma agalactiae strains: clues to the macro- and micro-events that are shaping mycoplasma diversity. BMC Genomics, 11(86), 1471-2164. https://doi.org/10.1186/1471-2164-11-86

Pirali Kheirabadi, K. H., \& Ebrahimi, A. (2007) Investigation of Mycoplasma agalactiae in Milk and Conjunctival Swab Samples from Sheep Flocks in West Central, Iran. Pakistan Journal of Biological Sciences, 10, 1346-1348. https://doi.org/10.3923/pjbs.2007.1346.1348

Schlehuber, L. D., McFadyen, I. J., Shu, Y., Carignan, J., Duprex, W. P., Forsyth, W. R., ... Lucier, S. C. (2011). Towards ambient temperature-stable vaccines: the identification of thermally stabilizing liquid formulations for measles virus using an innovative high-throughput infectivity assay. Vaccine, 29(31), 5031-5039. https://doi.org/10.1016/j.vaccine.2011.04.079

Sirand-Pugnet, P., Lartigue, C., Marenda, M., Jacob, D., Barré, A., Barbe, V., ... De Daruvar, A. (2007). Being pathogenic, plastic, and sexual while living with a nearly minimal bacterial genome. PLoS genetics, 3(5), e75. https://doi.org/10.1371/journal.pgen.0030075

Soria-Guerra, R. E., Nieto-Gomez, R., Govea-Alonso, D. O., \& Rosales-Mendoza, S. (2015). An overview of bioinformatics tools for epitope prediction: implications on vaccine development. Journal of biomedical informatics, 53, 405-414. https://doi.org/10.1016/j.jbi.2014.11.003

Soria-Guerra, R. E., Nieto-Gomez, R., Govea-Alonso, D. O., \& Rosales-Mendoza, S. (2015). An overview of bioinformatics tools for epitope prediction: implications on vaccine development. Journal of biomedical informatics, 53, 405-414. https://doi.org/10.1016/j.jbi.2014.11.003

Sotoodehnia, A., \& Arabi, I. (1986). Agalactia disease and its geographical distribution in sheep and goats in Iran. Archives of Razi Institute, 36(37), 75-78. 
Southwood, S., Sidney, J., Kondo, A., del Guercio, M. F., Appella, E., Hoffman, S., ... \& Sette, A. (1998). Several common HLA-DR types share largely overlapping peptide binding repertoires. The Journal of Immunology, 160(7), 3363-3373. http://www.jimmunol.org/content/160/7/3363

Stear, M. J. (2005). OIE Manual of Diagnostic Tests and Vaccines for Terrestrial Animals (5 ed.). Parasitology; Cambridge, Paris, France: Chapter 2.7.5.

Tola, S., Angioi, A., Rocchigiani, A. M., Idini, G., Manunta, D., Galleri, G., \& Leori, G. (1997). Detection of Mycoplasma agalactiae in sheep milk samples by polymerase chain reaction. Veterinary microbiology, 54(1), 17-22. https://doi.org/10.1016/S0378-1135(96)01269-2

Tola, S., Idini, G., Manunta, D., Galleri, G., Angioi, A., Rocchigiani, A. M., \& Leori, G. (1996). Rapid and specific detection of Mycoplasma agalactiae by polymerase chain reaction. Veterinary Microbiology, 51(1), 77-84. https://doi.org/10.1016/0378-1135(96)00023-5

Tola, S., Manunta, D., Rocca, S., Rocchigiani, A. M., Idini, G., Angioi, P. P., \& Leori, G. (1999). Experimental vaccination against Mycoplasma agalactiae using different inactivated vaccines. Vaccine, 17(22), 2764-2768. https://doi.org/10.1016/S0264-410X(99)00070-5

Van Kuppeveld, F. J., Van der Logt, J. T., Angulo, A. F., Van Zoest, M. J., Quint, W. G., Niesters, H. G., ... \& Melchers, W. J. (1992). Genus-and species-specific identification of mycoplasmas by $16 \mathrm{~S}$ rRNA amplification. Applied and environmental microbiology, 58(8), 2606-2615.

Wang, P., Sidney, J., Dow, C., Mothe, B., Sette, A., \& Peters, B. (2008). A systematic assessment of MHC class II peptide binding predictions and evaluation of a consensus approach. PLoS computational biology, 4(4), 148-156. https://doi.org/10.1371/journal.pcbi.1000048

Wang, P., Sidney, J., Kim, Y., Sette, A., Lund, O., Nielsen, M., \& Peters, B. (2010). Peptide binding predictions for HLA DR, DP and DQ molecules. BMC bioinformatics, 11(1), 568. https://doi.org/10.1186/1471-2105-11-568

Zendulkova, D., Madanat, A., Lany, P., Rosenbergova, K., \& Pospíšil, Z. (2007). Detection of Mycoplasma agalactiae by Polymerase Chain Reaction in Jordanian sheep and goat herds. Acta Veterinaria Brno, 76(1), 71-77. https://doi.org/10.2754/avb200776010071

\section{Copyrights}

Copyright for this article is retained by the author(s), with first publication rights granted to the journal.

This is an open-access article distributed under the terms and conditions of the Creative Commons Attribution license (http://creativecommons.org/licenses/by/4.0/). 